\title{
125 \\ Cognitive Factors in Design: Basic Phenomena in Human Memory and Problem Solving
}

\author{
Thomas T. Hewett \\ Department of Psychology, Sociology, and Anthropology \\ Drexel University \\ Philadelphia, PA 19104 USA \\ +01-215-895-2461, or 1313 \\ hewett@duvm.ocs.drexel.edu
}

\begin{abstract}
This tutorial provides a "hands-on" (actually, "minds-on") exploration of several basic processes and phenomena ofhuman memory, and problem solving. The emphasis is on developing both intuitiveand formal knowledge which can serve as background knowledge which will be useful in interpreting design guidelines and in making educateddesign judgments when design guidelines fail, conflict, or are nonexistent. Thedemonstrations used emphasize basic general phenomena with which any theory ofmemory or problem solving must deal. In addition, the tutorial suggests some ofthe implications of these phenomena for designing interactive computingsystems.
\end{abstract}

KEYWORDS: Memory, Problem Solving, Design,Models of the User

\section{INTRODUCTION AND CAVEATS}

The emphasis in this tutorial is on demonstrations and exercises which highlightsome of the quite remarkable things human beings do in interacting with, inlearning about, and in making sense out of the world around them. These thingsoften seem to be quite ordinary simply because we do them regularly, often without deliberation.Nonetheless, some of them are quite complex and not well understood. Many ofthe demonstrations replicate phenomena studied under controlled laboratoryconditions and some are drawn directly from research studies.

Since this tutorial emphasizes the development of anintuitive feel for the material, it is important to recognize that an intuitiveunderstanding must be informed and validated by research results. Ever sinceits founding, the findings of Experimental Psychology have taught us not to trust unsupportedpersonal hunches and intuitions about the reasons for human behavior. There area variety of ways in which ordinary day-to-day intuitions about behavior, bothour own and that of others, can lead one astray (some are illustrated in the tutorial). Mostof the demonstrations used in this tutorial are designed to replicate phenomenawhich have been studied or validated under controlled laboratory conditions. Infact, several of the demonstrations are drawn directly from research studies, although someprocedural license is taken for purposes of demonstration..

\section{MEMORY}

In one model of memory, short-term memory (STM) isdescribed (e.g., Solso, 1994) as having a limited storage capacity (seven plus or minus two chunks) for arelatively brief duration (estimates range from 12 to 30 seconds withoutrehearsal). Information can be maintained in STM for longer periods of timewith maintenance rehearsal (MR), although this simple repetition of material does not appear to be very efficient at transferring information intoLong Term Memory (LTM). Rather, elaborative rehearsal (ER) appears to be themost effective set of processes for the transfer of information into longtermstorage. Although the information in STM is usually thought to be represented by one of a relativelylimited number of codes, there are several reasons to believe that anyorganizational structure in LTM is accessible as a basis for forming the chunksthat are held in STM. 
LTM has a large capacity for storage of information for long periods of time.There is, however, no easy or obvious way to determine the limits of how muchcan be stored, or for how long it can be stored. Several types of informationare represented in LTM, including such things as facts and events, motor and perceptual skills,knowledge of physical laws and systems of mathematics, a spatial model of theworld around us, attitudes and beliefs about oneself and others, etc. Thisinformation is more or less well organized in a variety of ways and varies in its accessibility as afunction of several factors. The factors determining accessibility of theinformation in LTM include such things as the conditions which existed at thetime the information was stored, the recency of its last use, its degree of inter-relationship with otherknowledge, its degree of uniqueness relative to other information, etc. Mostdiscussions of failure to recall information from LTM focus on explanations suchas interference, the absence or inappropriateness of retrieval cues, or some type of organicdysfunction such as brain damage.

An alternative model of human memory holds that there is no need to postulate aSTM. Rather, there is a working memory which is part of the larger memorysystem and not a separate memory. Different degrees of persistence ofinformation in memory are thought to be a function of the elaborateness or the depth to which information hasbeen processed. The greater the degree of processing, the longer the retention period. In this model, chunks are organizational units in LTM andthe capacity limitation is on how much information can be actively scanned orheld in working memory at any time.

While the bulk of the evidence supports the model whichincludes working memory (Anderson, 1994), there are basic phenomena with which any theory of memory must deal. Forexample, regardless of whether one thinks of the seven plus or minus twocapacity limitation as the result of a limited capacity memory or as a resultof a limit on the amount of information which can be activated and maintained inan active state in working memory at any given time, it is clear that there is acapacity limitation. Similarly, regardless of whether one thinks that memoryrehearsal processes have different degrees of depth and elaboration or that there are twodifferent kinds of rehearsal processes, each associated with a different memorystore, it is clear that elaborative rehearsal is more effective than maintenancerehearsal in insuring that the information will be accessible in memory for a long period of time.

\section{PROBLEM SOLVING}

A major turning point in the literature on problem solvingoccurred with the work of Newell and Simon (1972). In their view, a problem can be analyzed by means of a "problem space"representing various states of knowledge of the problem solver, a series oftransformations between states, and a set of operators which produce thosetransformations. A problem exists when we have a gap between an initial state and a goal state. The means of solving the problem involves applying the appropriateset of operators required to complete a series of state transformations thatwill eliminate the gap. These transformations must be accomplished withoutviolating any of the conditions on the operators.

As a result of repeated experience with problems, solversbuild up an organized body of knowledge or information about the properties of aparticular type of problem and the operations or steps required to solve it.This organized body of information is usually referred to as a problem solving schema (e.g.,Norman, 1982). Humans develop a wide variety of familiar problem schemas(Hayes, 1981), and the typical individual has built up a wide stock of such schemas whichcome into play in solving problems problems with which one has prior experience.Some schemas are so familiar they are activated almost automatically and withoutmuch thought.

Typically, the effect of problem solving schemas is tohelp provide reasonably efficient methods of solving frequently encountered kinds of problems. Sometimes, however, a schema caninterfere with the problem solving process. Since it influences the problemsolver's early analysis of the problem and determines which schema, or schemas, will be brought to bear in solving a particular problem, the way in which that problem is represented canmake a vital difference in how easily the problem can be solved. When a problemis not solved as easily as expected. it is often quite fruitful to look to theadequacy of the representation of the problem, and to give thought to somehow modifying orchanging that representation.

\section{SOME IMPLICATIONS FOR HUMAN. COMPUTER INTERACTION DESIGN}

In considering the nature of human memory it is clear that designers need totake account of the fact that there are a limited number of "chunks" ofinformation with which a user can actively cope at any given time. While thesize of those chunks can be affected by the development of 
additional new knowledge structures, that growthof knowledge requires that the user be actively engaged in elaborating and assimilating that knowledge. Inaddition the demands upon human learning and memory can be reduced by providingappropriate mnemonic cues in the interface and the flow of interaction. Inconsidering the nature ofhuman problem solving it is clear that designers need to take account of thefact that users will bring to bear established problem solving strategies whichare developed from having solved problems encountered frequently in the past. While these established strategies can be used to facilitate usage they can also create processblockages which may only be solved by changing the way the problems ofinteraction are presented to the user or by creating a working environment inwhich the user has the flexibility to redefine, reconceptualize or rerepresent the tasks or problems which thesoftware is being used to solve.

Among the more general implications of the phenomenadescribed above for human-computer interaction design, two stand out. The first, derived from consideration of the nature of long term memory and the processesgoverning storage and retrieval of information, is that humans interacting withcomputers can and do use existing memories and memory structures to assign aninterpretation to a wide variety of things, regardless of whether that meaningwas intended by the designers. The second major implication, derived fromconsideration of the nature of the way people solve problems is that, people,"...do not do what designers want them to do; instead they tend to get activelyinvolved and to think and plan and solve problems (Carroll \& Mack,1985)."

\section{REFERENCES}

1. Anderson, J. R. CognitivePsychology and Its Implications. 4th ed. W. H. Freeman, New York,NY, 1994.

2. Carroll, J. M., and Mack, R. L.Metaphor, computing systems, and active learning. Int. J. ofMan-Machine Studies, 22, 1, (1985), 39-57.

3. Hayes, J. R. The CompleteProblem Solver. The Franklin Institute Press, Philadelphia, PA,1981.

4. Newell, A., and Simon, H. A.Human Problem Solving. Prentice-Hall, EnglewoodCliffs, NJ, 1972.

5. Norman, D. A. Learning andMemory. New York: W. H. Freeman, New York, NY, 1982.

6. Solso R. L. CognitivePsychology. 4th ed. Allyn and Bacon, Needham Heights, MA,1994. 